\title{
Estratégia de aprendizagem de Anatomia Humana no ciclo básico de Medicina num contexto de pandemia: relato de experiência com o uso do instagram
}

\author{
Learning estrategy of Human Anatomy in basic Medical curriculum in a pandemic context: \\ experience report using instagram \\ Estrategia para el aprendizaje de la Anatomía Humana en el ciclo básico de Medicina en un \\ contexto pandémico: informe de experiencia con el uso de instagram
}

Júlia Rachel Ferreira Meneses ORCID: https://orcid.org/0000-0002-1924-4668 Faculdade de Ciências Humanas, Exatas e de Saúde do Piauí, Brasil E-mail: juliarachelfm@hotmail.com

Hugo Feliphy Pereira Rocha ORCID: https://orcid.org/0000-0002-3082-185X Faculdade de Ciências Humanas, Exatas e de Saúde do Piauí, Brasil E-mail: felipyrocha@gmail.com

Karla Emília Lima da Silveira ORCID: https://orcid.org/0000-0002-6438-7705 Faculdade de Ciências Humanas, Exatas e de Saúde do Piauí, Brasil E-mail: 1karlaemilia@gmail.com

Ana Vitória Dias de Sousa

ORCID: https://orcid.org/0000-0001-5932-4294 Faculdade de Ciências Humanas, Exatas e de Saúde do Piaú, Brasil E-mail: anavitoria_dp@hotmail.com

Antônio Victor Azevedo Sena ORCID: https://orcid.org/0000-0002-2136-962X Faculdade de Ciências Humanas, Exatas e de Saúde do Piauí, Brasil E-mail: victorazevedo751@gmail.com

Maria Fernanda Araújo de Miranda ORCID: https://orcid.org/0000-0002-5403-9280 Faculdade de Ciências Humanas, Exatas e de Saúde do Piaú, Brasil

E-mail: mariafernandamfam6@gmail.com

Bruna Caroline Ribeiro Beltrão

ORCID: https://orcid.org/0000-0002-5894-5627 Faculdade de Ciências Humanas, Exatas e de Saúde do Piauí, Brasil E-mail: brunacrbeltrao@gmail.com

Francisco Vinnicius Monteiro Gomes ORCID: https://orcid.org/0000-0002-2370-3062 Faculdade de Ciências Humanas, Exatas e de Saúde do Piauí, Brasil E-mail: fvmg116@gmail.com

Antonione Santos Bezerra Pinto ORCID: https://orcid.org/0000-0002-6577-2816 Faculdade de Ciências Humanas, Exatas e de Saúde do Piauí, Brasil

E-mail: Antonione.pinto@iesvap.edu.br

Ana Rachel Oliveira de Andrade ORCID: https://orcid.org/0000-0002-8981-0856 Faculdade de Ciências Humanas, Exatas e de Saúde do Piauí, Brasil E-mail: ana.andrade@iesvap.edu.br

Francisco das Chagas Candeira Mendes Júnior ORCID: https://orcid.org/0000-0003-1511-517X Faculdade de Ciências Humanas, Exatas e de Saúde do Piauí, Brasil E-mail: fcmendesjrfisio@gmail.com

José Lopes Pereira Júnior ORCID: https://orcid.org/0000-0001-5621-7469 Faculdade de Ciências Humanas, Exatas e de Saúde do Piauí, Brasil E-mail: josejrfarmaceutico@gmail.com Leonardo Ferreira Braz Lima ORCID: https://orcid.org/0000-0003-0892-8914 Faculdade de Ciências Humanas, Exatas e de Saúde do Piaú, Brasil E-mail: Leonardo.lima@iesvap.edu.br 
Tereza Cristina de Carvalho Souza Garcês ORCID: https://orcid.org/0000-0001-6337-5166 Faculdade de Ciências Humanas, Exatas e de Saúde do Piauí, Brasil E-mail: tereza.garces@iesvap.edu.br

Antônio de Pádua Rocha Nóbrega Neto ORCID: https://orcid.org/0000-0003-4829-0062 Faculdade de Ciências Humanas, Exatas e de Saúde do Piaú, Brasil E-mail: antonio.neto@iesvap.edu.br

\begin{abstract}
Resumo
Objetivo: O artigo visa relatar a experiência da elaboração de uma página no Instagram como ferramenta facilitadora para adesão dos acadêmicos da disciplina de anatomia em meio à pandemia da Covid-19. O trabalho foi desenvolvido por acadêmicos do $2^{\circ}$ período de medicina, da Faculdade de Ciências Humanas, Exatas e da Saúde do Piauí FAHESPIESVAP, no município de Parnaíba-PI. Metodologia: Estudo descritivo, do tipo relato de experiência, descrevendo os passos da criação de uma rede de compartilhamento para a turma na rede social instagram, onde ocorreu a veiculação de imagens das peças anatômicas e, posteriormente, a avaliação de sua influência no processo de aprendizagem, por meio de um quiz. Resultados e discussão: A experiência de administrar uma página de Instagram como acadêmica de medicina trouxe a possibilidade de desenvolver habilidades como a responsabilidade e compromisso, visto a necessidade de embasamento científico, a fim de evitar a propagação de informações erradas e, consequentemente, o aprendizado errado. Conclusão: Foi observado que a abordagem utilizada na busca de estratégias que ampliem a convivência do aluno com os assuntos da disciplina de anatomia humana teve boa aceitação dos indivíduos, evidenciando o alto alcance do público. Contribuiu para o acesso e para o aprendizado de Sistemas Orgânicos Integrados aplicados à anatomia humana, favorecendo a familiarização do aluno com a disciplina, visto que os conteúdos estão dispostos em uma plataforma na qual frequentam diariamente, possibilitando aumentar o engajamento dos mesmos nas aulas práticas em laboratório.
\end{abstract}

Palavras-chave: Pandemia; Instagram; Aprendizagem compartilhada; Anatomia.

\begin{abstract}
Objective: This article aims to describe the elaboration of an instagram page experience as a facilitation tool to adherence of anatomy students inside the COVID-19 pandemic. This proposal was made by second grade medical students from Faculdade de Ciências Humanas, Exatas e da Saúde do Piauí in Parnaíba-PI. Methodology: Descriptive study, experience report's type, describing the steps of creating a sharing network for the class on social media instagram, where the sharing of images of the anatomical pieces occurred and, subsequently, the evaluation of their influence on the learning process, through a quiz. Results and discussion: The experience of managing an Instagram account as a medical student brought the possibility of developing skills such as responsibility and commitment, given the need for scientific basis, in order to avoid the spread of wrong information and, consequently, the wrong learning. Conclusion: It was observed that the approach used in the search for strategies that expand the student's coexistence with the subjects of human anatomy was well accepted by the individuals, evidencing the high reach of the public. This contributed to the access and learning of Integrated Organic Systems applied to human anatomy, favoring the student's familiarization with the discipline, since the contents are arranged on a platform on which they attend daily, making it possible to increase their engagement in practical laboratory classes.
\end{abstract}

Keywords: Pandemic; Instagram; Shared learning; Anatomy.

\title{
Resumen
}

Objetivo: El artículo tiene como objetivo reportar la experiencia de crear una página de Instagram como herramienta facilitadora para la adhesión de estudiantes de anatomía en medio de la pandemia Covid-19. El trabajo fue desarrollado por académicos del $2^{\circ}$ período de la Medicina, de la Facultad de Ciencias Humanas, Exactas y de la Salud de Piauí FAHESP-IESVAP, en la ciudad de Parnaíba-PI. Metodología: Estudio descriptivo, del tipo relato de experiencia, describiendo los pasos de creación de una red de intercambio para la clase en la red social instagram, donde se mostraron imágenes de las piezas anatómicas y, posteriormente, la evaluación de su influencia en el proceso de aprendizaje. a través de un cuestionario. Resultados y discusión: La experiencia de administrar una página de Instagram como estudiante de medicina trajo la posibilidad de desarrollar habilidades como la responsabilidad y el compromiso, dada la necesidad de base científica, para evitar la difusión de información incorrecta y, en consecuencia, el aprendizaje incorrecto. Conclusión: Se observó que el abordaje utilizado en la búsqueda de estrategias que amplíen la convivencia del estudiante con los sujetos de la disciplina de anatomía humana fue bien aceptado por los individuos, evidenciando el alto alcance de público. Contribuyó al acceso y aprendizaje de Sistemas Orgánicos Integrados aplicados a la anatomía humana, favoreciendo la familiarización del alumno con la disciplina, ya que los contenidos se ordenan en una plataforma a la que asisten diariamente, posibilitando incrementar su participación en las clases prácticas en laboratorio. Palabras clave: Pandemia; Instagram; Aprendizaje compartido; Anatomía. 


\section{Introdução}

A pandemia da COVID-19, doença causada pelo coronavírus, foi reconhecida pela Organização Mundial da Saúde (OMS) em março de 2020. (Oms, 2020). Devido à inexistência de medidas específicas para a COVID-19, e sua rápida taxa de transmissão e contaminação, a OMS recomendou a adoção de medidas, dentre as quais, destaca-se a restrição social (Garcia; Duarte, 2020).

Conforme enfatizam Santana et al, "a questão do distanciamento social e da quarentena em que nos encontramos tem trazido consigo uma série de mudanças em nossas formas de ser e estar no mundo, cada vez mais mediadas pelo digital em rede" (Santana et al., 2020, p 302).

Devido a isso, o método de ensino do curso de medicina foi temporariamente modificado e novas maneiras de abordar o ensino foram evidenciadas, dando destaque ao Regime Especial de Aprendizagem Remota (Cardoso, 2020). Sendo assim, debates foram ampliados acerca da metodologia de ensino, devido à necessidade de adaptação do ensino presencial ao cenário pandêmico e por ser um curso essencialmente prático (Gomes et al., 2020).

À vista disso, as aulas práticas de laboratório voltaram a ocorrer presencialmente, seguindo os protocolos de distanciamento social e de uso de equipamentos de proteção individual preconizados pela Agência Nacional de Vigilância Sanitária (Ferreira et al., 2021), a fim de diminuir a dificuldade de aprendizado dos discentes. No entanto, o curto espaço de tempo em contato com as peças anatômicas, as quais são compartilhadas entre os alunos durante 1 hora/semanal, e a inviabilização de frequentar os laboratórios em horários extras, não permitem a superação desse déficit (Brasil, 2020).

A mediação baseada nos critérios de Reuven Feuerstein, apresentada em Bertelli (2002), em meio a pandemia de coronavírus, fica comprometida, especialmente quando as metodologias do ensino presencial são reinventadas de modo a caber dentro de um novo modelo, agora de distanciamento social e vigilância redobradas (Rondini; Pedro; dos Santos Duarte, 2020).

$\mathrm{O}$ fato é que o aluno continua sendo mediado, mas alguns elementos de mediação acabam sendo perdidos nesse novo processo. Percebe-se que o sentimento de pertencimento dos acadêmicos durante o processo ensino-aprendizagem é comprometido devido ao tempo limitado, tanto com as peças anatômicas, quanto com seu círculo afetivo (Saldanha, 2020).

Dessa forma, já que condições de equidade não podem mais ser garantidas ao grupo de alunos, a dedicação e foco durante o momento de aula prática precisam ser intensos, e como forma de reforçar o aprendizado, surge a conduta de compartilhamento de informação sobre o objeto de estudo das aulas (Azevedo et al., 2021).

Nesse sentido, é possível pensar em novas dinâmicas que se estabelecem no trabalho educacional em um cenário pandêmico. Dentro desta nova cibercultura (Santos, 2019), os processos comunicacionais são recriados, de maneira a difundir novas práticas de leitura e aquisição de conhecimento, de acordo com Alves, Mota e Tavares (Alves; Mota; Tavares, 2018).

O fenômeno na plataforma Instagram denominado Studygram, palavra em inglês que une study (estudo) e Instagram, surge como uma ferramenta de estudo, permitindo estratégias educacionais compartilhadas. Consiste em um perfil cujo objetivo é divulgar fotos e stories do processo de estudo dos seus usuários, os Studygrammers, que agregam valor aos que os acompanham, demonstrando ser uma inovação na forma de aprender e de compartilhar conteúdos, além de manter o Studygrammer e seus seguidores motivados (Machado, 2018). Assim, o Studygram é auxiliar ao processo de ensinoaprendizagem ao possibilitar uma nova forma de produção e de recepção da informação, aproximando o acadêmico a assuntos médicos de forma interativa, diversificada e compartilhada (Biadeni; Castro, 2020).

O termo compartilhar para o dicionário Aurélio é o mesmo que "ter ou tomar parte em; participar de; partilhar, compartir, usar em comum". Aprendizagem, por sua vez, para o mesmo autor, é "o ato ou efeito de aprender, ou seja, processo pelo qual o indivíduo adquire saberes, conhecimentos, valores através de experiências, ensinamentos ou estudo". Deste modo, 
pode-se afirmar que a aprendizagem compartilhada se dá na partilha, de forma participativa e comunitária com vistas à união e crescimento conjunto na esfera acadêmica (Ferreira, 1998).

Na visão de Fernández, compartilhar o processo de ensino-aprendizagem "permite a utilização flexível e eficiente do tempo e se beneficia dos diferentes estilos de ensino, da colaboração entre indivíduos e da utilização de alternativas de ensino". Nesta perspectiva, Fernández salienta que o ensino compartilhado traz evidentes benefícios ao rendimento dos alunos. Estes devem e podem estar relacionados às trocas de informações, aos conhecimentos e às técnicas de ensino que o grupo tem condições de empreender nesta metodologia, ampliando, dessa maneira, os horizontes da aprendizagem (Fernández, 1993).

A movimentação do instagram “@conteudos.med” buscou minimizar os conflitos adaptativos trazidos com a pandemia, fornecendo elementos essenciais ao processo de aprendizagem, sistematização e gerenciamento dos conteúdos específicos privilegiando o interacionismo nas aprendizagens da área de saúde. Faz-se necessário um trabalho conjunto entre professores e acadêmicos para que seja possível mediar as atividades propostas no ambiente virtual com vistas à minimização do estranhamento dos alunos e a maximização das possibilidades de aprendizado.

Diante desse contexto, esse artigo tem por objetivo relatar a experiência da elaboração e utilização (alimentação) de uma página de studygram como ferramenta facilitadora para engajamento dos alunos da disciplina de Sistemas Orgânicos Integrados aplicado à anatomia humana no ciclo básico de medicina.

\section{Metodologia}

Trata-se de um estudo descritivo de abordagem quali-quantitativa, do tipo relato de experiência, realizado em maio de 2021 (Ludke; Andre, 2013). A utilização do Instagram como uma ferramenta para melhorar a adesão e o engajamento acadêmico ao laboratório de anatomia da disciplina Sistemas Orgânicos Integrados, foi realizada por iniciativa pessoal, de forma natural e, posteriormente, foi reforçada com ânimo pelo professor/orientador durante as práticas laboratoriais.

A conta "conteudos.med" na plataforma Instagram trata-se de um studygram de compartilhamento de fotos e vídeos curtos, por 24 horas ou por tempo indeterminado, no qual se difunde informações acerca dos assuntos do ciclo básico do curso de medicina.

Figura 1 - Perfil da conta conteudos.med.

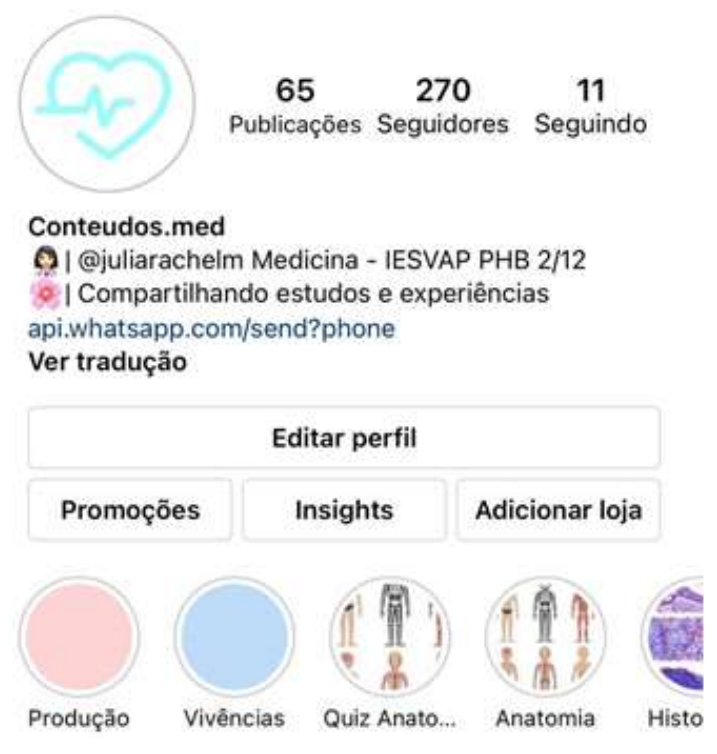

Fonte: Instagram. conteudos.med (2021). 
O nome da dinâmica desenvolvida, voltada para o aprendizado de anatomia humana, foi baseado no título da disciplina e na própria dinâmica utilizada, escolheu-se: "quiz de anatomia: responda e aprenda". Em seguida, a capa do destaque foi idealizada com foco principal nas seguintes características que fundamentam a disciplina: o público alvo, o meio ambiente e os instrumentos utilizados.

Figura 2 - Capa do destaque.

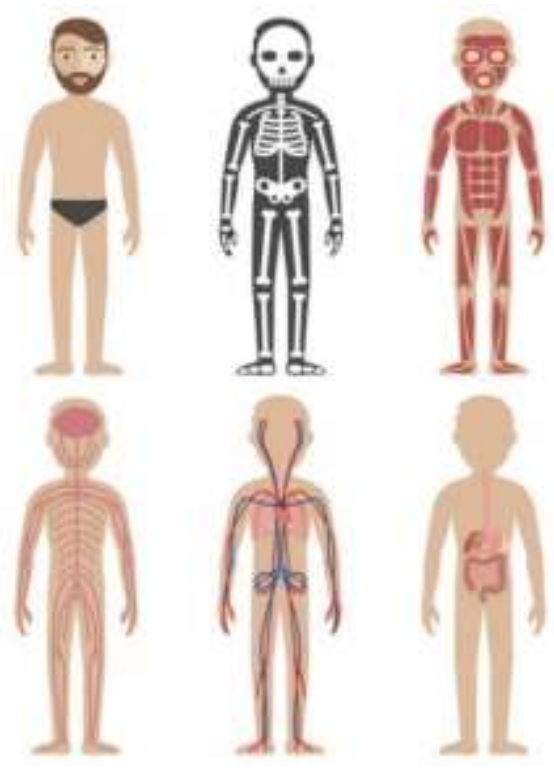

Fonte: Instagram. conteudos.med (2021).

Para captar a atenção e melhorar o empenho do usuário, foi criada uma identidade visual (como paletização de cores e padronização de fontes, fazendo com que os seguidores reconheçam a página a cada post publicado) e estabelecida uma constância em postagens com periodicidade definida (após as aulas de laboratório e na semana antes da prova prática).

Figura 3 - Identidade visual do quiz de anatomia.

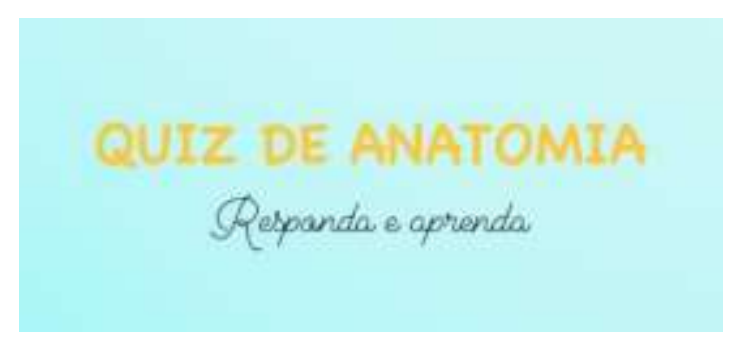

Fonte: Instagram. conteudos.med (2021).

Em vista disso, foram exploradas algumas tecnologias disponibilizadas no próprio aplicativo. As publicações ocorreram nos "stories" no formato de foto, recurso no qual a publicação fica disponível para a visualização durante 24 horas e, posteriormente, adicionados nos "destaques", recurso que disponibiliza a publicação por tempo indeterminado, com foco em aumentar o engajamento do público quanto ao aprendizado e à revisão (Martins; Albuquerque; Neves, 2018).

Os stories são utilizados semanalmente, com o compartilhamento de fotos das próprias peças utilizadas em laboratório com cada segmento anatômico evidenciado e nomeado. Todas as publicações são conferidas previamente pelo professor/orientador e o conteúdo das mesmas segue o planejamento do cronograma da disciplina. Assim, o conteúdo divulgado foi previamente visto em laboratório e serve como auxílio à fixação do conteúdo praticado em aula. 
Figura 4 - Exemplo de uma publicação nos stories.

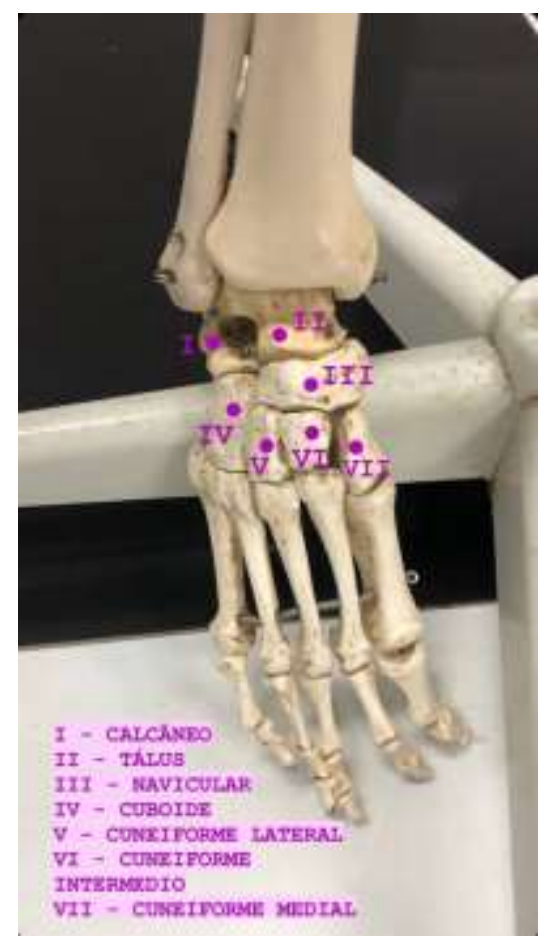

Fonte: Instagram. conteudos.med (2021).

A ferramenta "testes" foi utilizada para a criação do quiz "responda e aprenda", que consiste em perguntas feitas semanalmente sobre uma temática específica de anatomia humana, seguindo o cronograma da disciplina, visando a prática e fixação do conteúdo.

Essa ferramenta é de fácil acesso e prática, além de ser uma dinâmica de entretenimento, com uma abordagem diferente das páginas dos livros e dos testes em plataformas educacionais. Os stories são diretos e objetivos e o quiz proporciona uma experiência de estudo atraente, pois possui animações, sons e imagens durante o teste. O quiz permite uma autoavaliação e, assim que a questão é respondida, já é fornecido um feedback.

Figura 5 - Exemplo de uma questão do quiz "Responda e aprenda".

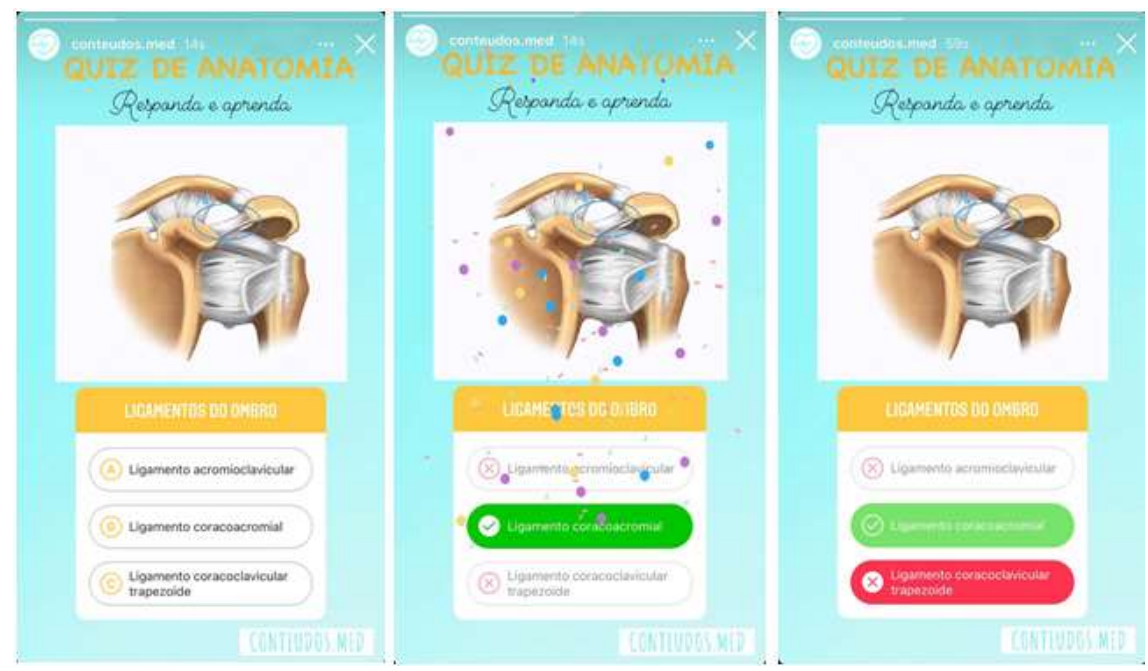

Fonte: Instagram. conteudos.med (2021). 
Outro ponto relevante é a presença de métricas. É possível ver quantos usuários visualizaram o teste e quantos escolheram cada alternativa. Na Figura 6 é possível observar que o questionário teve 23 participantes e a quantidade de respostas em cada uma das alternativas.

Figura 6 - Métrica quantitativa do aplicativo sobre uma questão realizada.

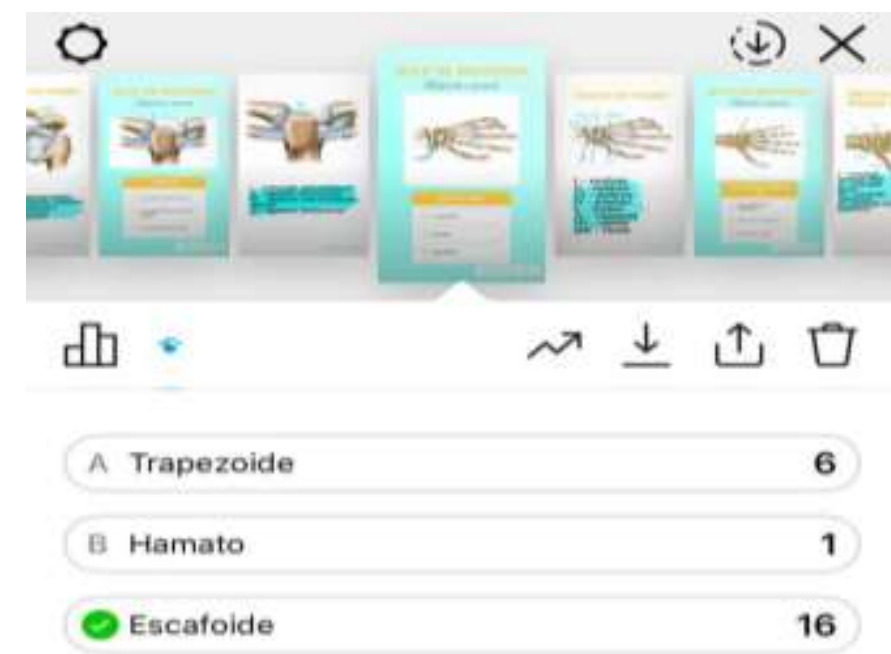

Fonte: Instagram. conteudos.med (2021).

A interação dos alunos também foi observada através de comentários feitos através do direct, recurso que permite a troca de mensagens e de fotos de forma privada com seus seguidores. obtendo alguns comentários de opiniões de alunos.

Figura 7 - Feedback de alguns seguidores e estudantes de medicina.

Olá Jülia, é muito interessante estudar anatomia no seu insta, pois torna o conteúdo das aulas bem acessiveis e é bem mais prático buscarmos uma informaçäo aqui ou relembrarmos algo. Outra coisa que queria ressaltar é que as imagens sempre vem acompanhada dos nomes das partes anatômicas realmente no local, sầ bem nitidas e o também tem uma organização muito boa, o que facilita demais minha busca $e$ aprendizagem.

Júlia, agradeço por demais pelo seu Instagram conteúdos.med, pois através dele pude fixar melhor os conteúdos de anatomia, uma vez que você traz imagens bem ilustrativas $e$ as apresenta de uma forma bem didática, ajudando no aprendizado. Também adoro quando você traz testes em forma de cards, ajudam bastante para aprender o assunto.
Olá, vejo este instagram como uma forma de sedimentar minhas ideias e também me apresenta várias informaçōes que ainda năo tinha aprendido

E além do mais, é muito legal que seja pela plataforma do Instagram, pois, quando eu entro no instagram, em vez de ver coisas fúteis, eu posso responder os quiz, e aprender mais... Entāo, muito obrigada por essa criação que tornou o Instagram útil na minha vida e de muita gente.

Seu intragram tem me agregado muito!Seus storys salo como uma revisăo aplicando a técnica de recordaçāo ativa.

Isso vem fortalecento um importante pilar para o deservolvimento da minha aprendizagem em anatomia.

Fonte: Instagram. conteudos.med (2021). 
Tais evidências, sustentam o resultado positivo obtido através do instagram conteudos.med como ferramenta educacional e de engajamento.

\section{Resultados e Discussão}

As postagens de peças anatômicas e o quiz de anatomia no instagram “@ conteudos.med” tiveram início no dia 08/03, e até o dia 24/05 apresentaram uma boa aceitação, com um total de 270 seguidores, obtendo alcance (1744 contas) e impressões (30438) surpreendentes, conforme relatório gerado dos últimos 30 dias.

Figura 8 - Desempenho da conta.

\section{Acompanhe seu desempenho}

Você alcançou 1.744 contas nos últimos 30 dias.

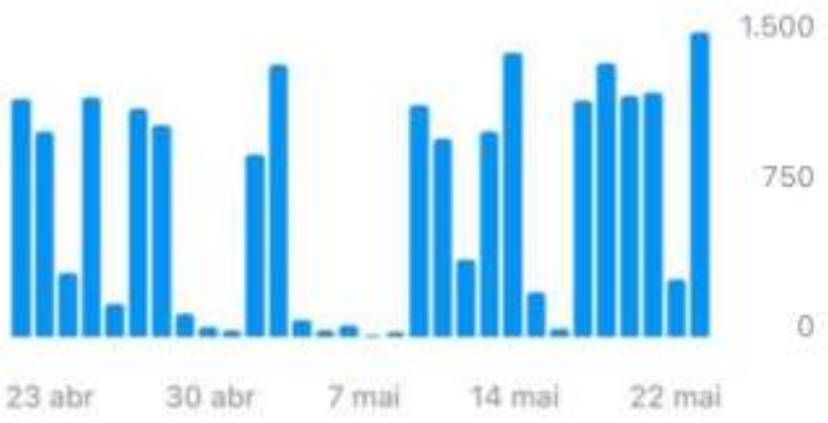

Fonte: Instagram. conteudos.med (2021)

Figura 9 - Interações com o conteúdo.

Interações com publicaçőes

v5. 7 abr -6 mai

Curtidas

Comentários

Salvamentos

Interações com stories

v5. 7 abr -6 mal

Respostas

Compartilhamentos
140

127

9

4

29

11

18

Fonte: Instagram. conteudos.med (2021). 
Figura 10 - Impressões da conta.

Impressões

\section{Atividade do perfil}

vs, 7 abr -6 mai

Visitas ao perfil

Toques no site
30.438

941

18

Fonte: Instagram. conteudos.med (2021).

No mês de março, foram feitas publicações e stories sobre neuroanatomia, com imagens das próprias peças anatômicas disponibilizadas em laboratório e informações complementares dos slides disponibilizados pelo professor/orientador.

Figura 11 - Produções de neuroanatomia.
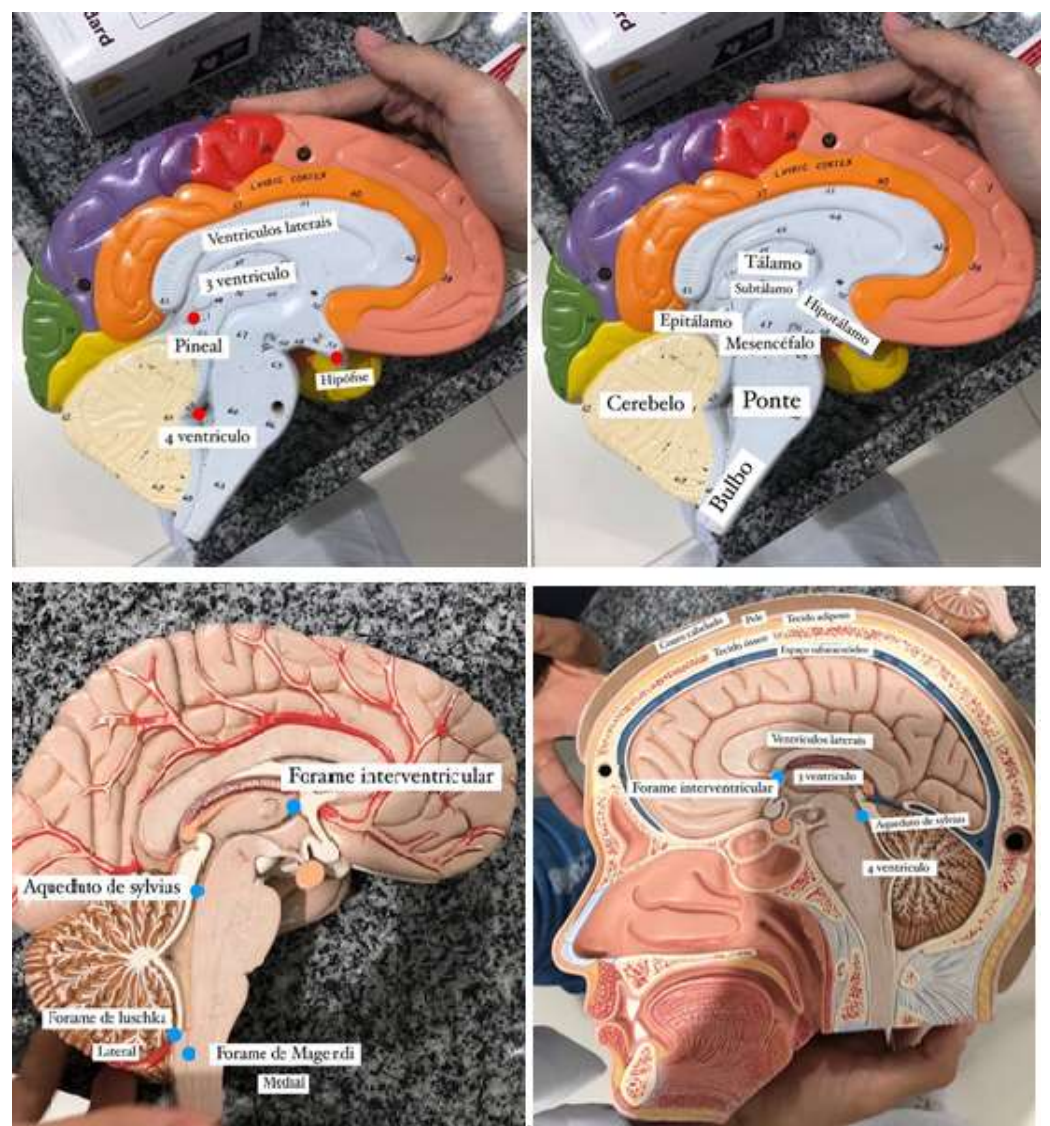

Fonte: Instagram. conteudos.med (2021).

No mês de abril, o conteúdo de anatomofisiologia renal foi abordado por meio de stories com imagens das peças disponibilizadas em laboratório e com informações ministradas pelo professor/orientador durante as aulas práticas. 
Figura 12 - Produções de anatomofisiologia renal.
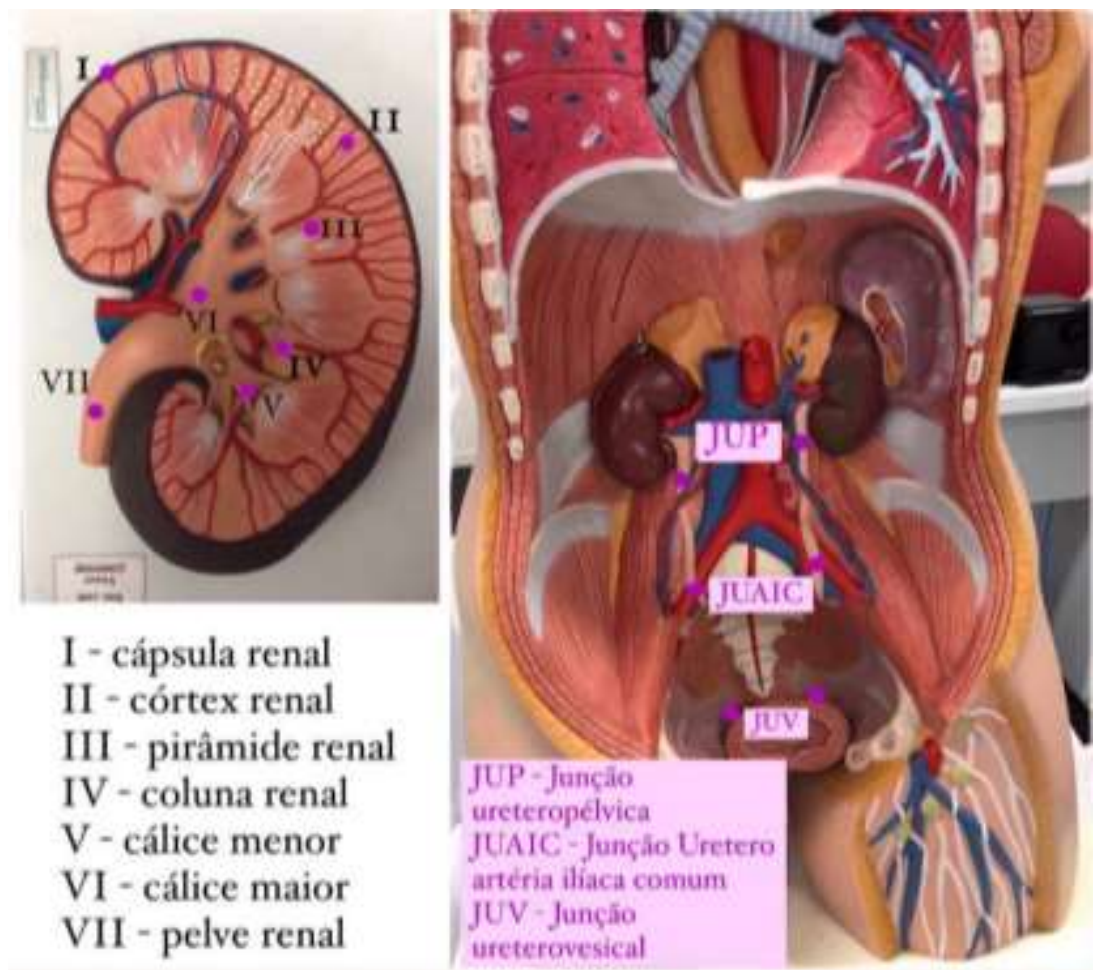

Fonte: Instagram. conteudos.med (2021).

No mês de maio, foram postados stories sobre anatomia do aparelho genital feminino e masculino e do aparelho locomotor e realizado um quiz dinâmico abordando o aparelho locomotor (membros superiores e inferiores), com imagens das próprias peças anatômicas disponibilizadas em laboratório e retiradas do aplicativo "HiDoctor Atlas" e do livro "Anatomia clínica de Netter”. (Hansen; Lambert; Oppido, 2007).

Figura 13 - Produções do aparelho genital feminino.

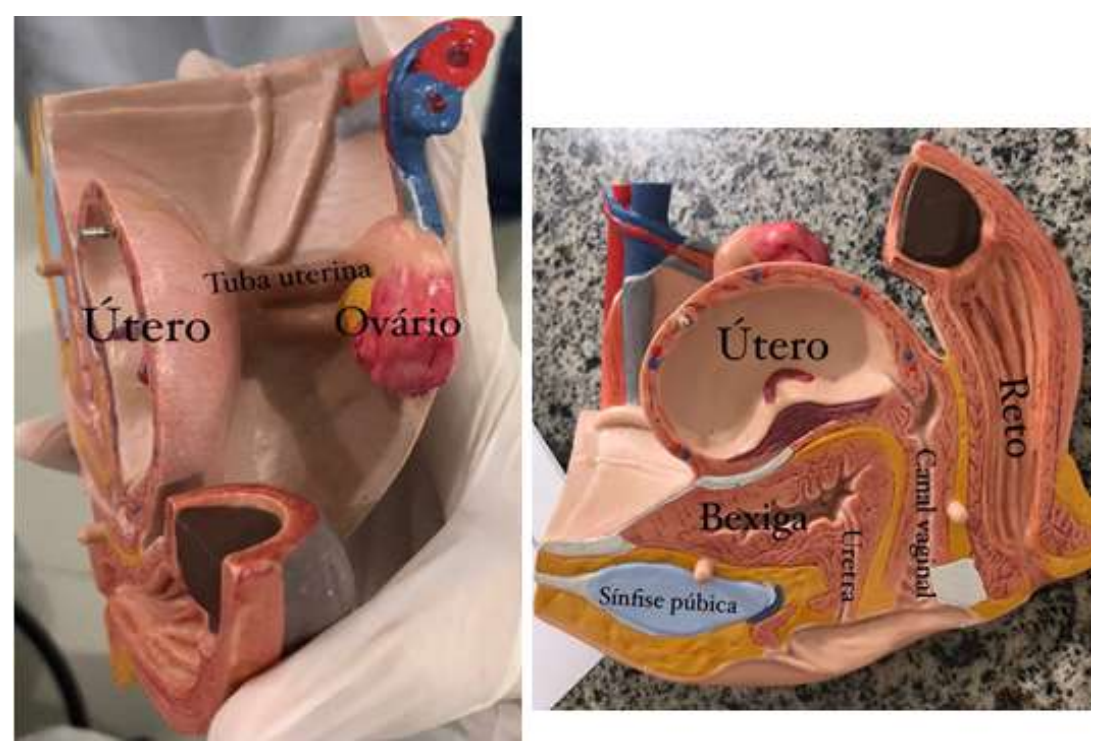

Fonte: Instagram. conteudos.med (2021). 
Research, Society and Development, v. 10, n. 7, e42110716923, 2021

(CC BY 4.0) | ISSN 2525-3409 | DOI: http://dx.doi.org/10.33448/rsd-v10i7.16923

Figura 14 - Produções do aparelho genital masculino.

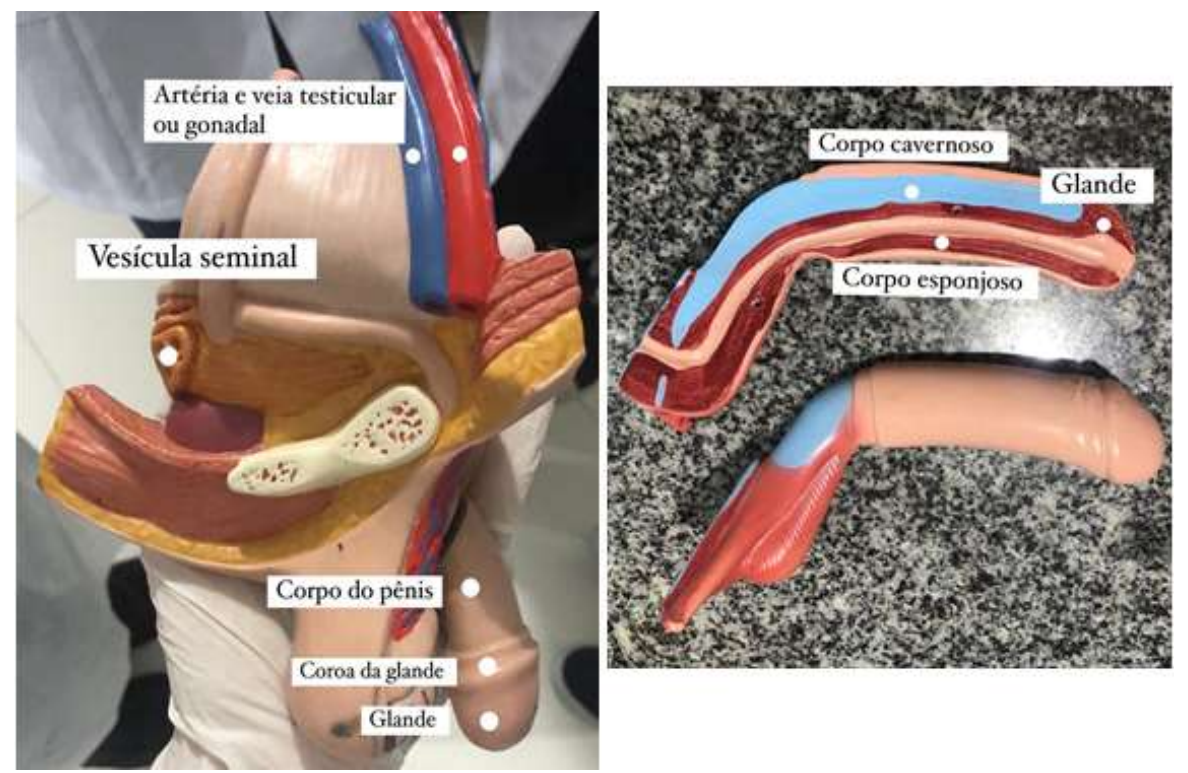

Fonte: Instagram. conteudos.med (2021).

Figura 15 - Produções do aparelho locomotor.

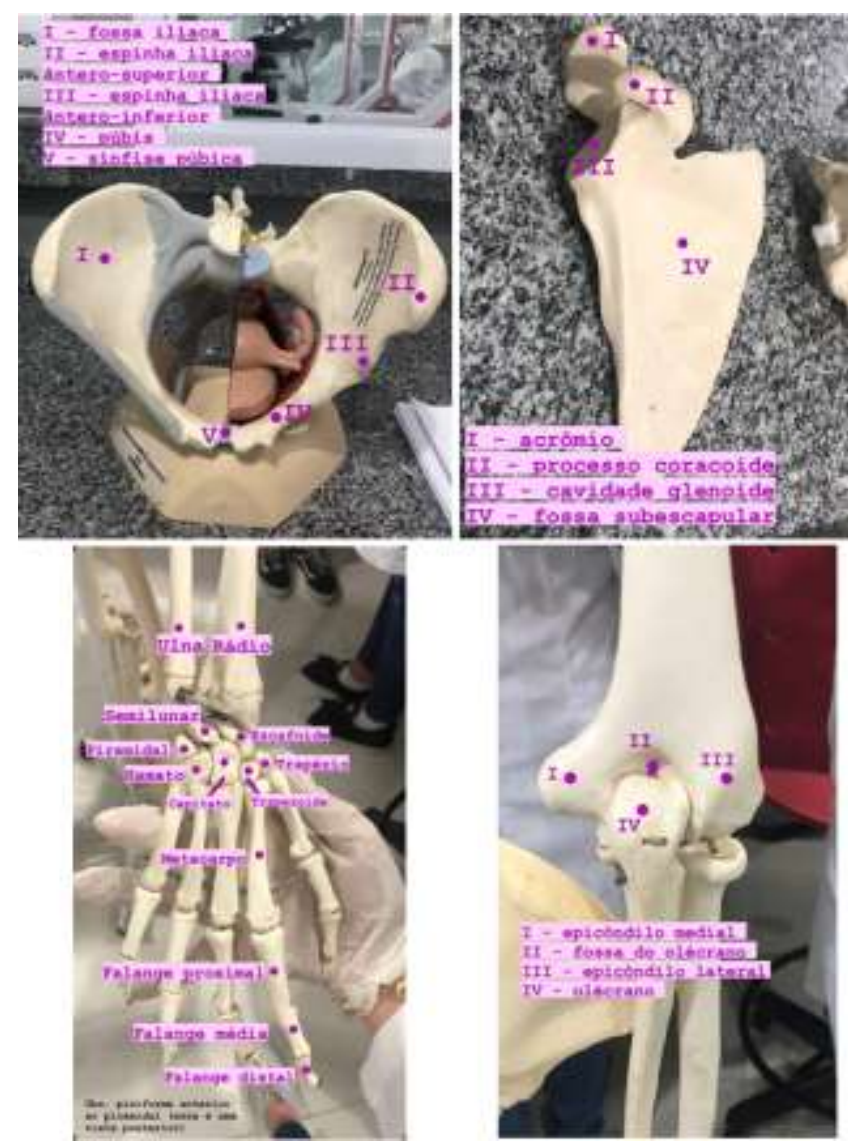

Fonte: Instagram. conteudos.med (2021). 


\section{Conclusão}

A utilização do Instagram na disciplina Sistemas Orgânicos Integrados voltada para anatomia, pôde proporcionar aos acadêmicos uma forma criativa e dinâmica de reforçar o conhecimento prático, visando diminuir a distância entre as peças anatômicas e os alunos e aumentar a fixação do conteúdo, visto o cenário pandêmico, no qual os laboratórios não são disponibilizados para estudos pós-aula.

A experiência de administrar uma página de Instagram como acadêmica de medicina foi engrandecedora, pois trouxe a possibilidade de desenvolver habilidades como a responsabilidade e compromisso, visto a necessidade de que cada postagem seja verídica e tenha embasamento científico, a fim de evitar a propagação informações erradas e, consequentemente, o aprendizado errado.

Portanto, conclui-se que, com a abordagem utilizada, seguindo o cronograma da disciplina Sistemas Orgânicos Integrados e, evidenciando o alto alcance do público por meio da plataforma Instagram, essa iniciativa favoreceu a formação do aluno, visto que os conteúdos estão dispostos em uma plataforma na qual frequentam diariamente, impactando positivamente no aprendizado dos mesmos. Assim, reforça-se a ideia que as redes sociais podem estar integradas ao processo de ensino e aprendizagem de anatomia no Ciclo Básico de medicina pelas potencialidades de disseminação das informações e por ser parte do cotidiano dos acadêmicos.

\section{Agradecimentos}

Agradecemos ao Prof ${ }^{\mathrm{D}}$ Antonio de Pádua Rocha Nóbrega Neto pelo incentivo, apoio técnico na escolha e suporte com o tema.

\section{Referências}

Alves, L. A., Mota, F. M., \& Tavares, P. T. (2018). O instagram como processo de engajamento das práticas educacionais: a dinâmica para a socialização do ensino-aprendizagem. Revista Científica da Fasjete,(19).

announces COVID, W. H. O. (2020). outbreak a pandemic. Geneva, Switzerland: World Health Organization.

Azevedo, J. L., de Oliveira, A. A., Nascimento, J. S., \& Gomes, L. P. (2021). Instagram como ferramenta de mediação da aprendizagem: uma nova forma de se aproximar do aluno utilizando a tecnologia. Brazilian Journal of Development, 7(3), 31191-31200.

Bertelli, A. R. (2002). Aprendizagem Mediada Dentro e Fora da Sala de Aula. São Paulo: Editora Senac.

Biadeni, B. S., \& Castro, G. G. (2020). Studygrams: promovendo o consumo de modos de ser e estudar em plataformas digitais. Fronteiras-estudos midiáticos, 22(1), 72-83.

Brasil. Ministério da Saúde. Agência Nacional de Vigilância Sanitária -ANVISA. Nota Técnica No 04/2020. Orientações para serviços de saúde: medidas de prevenção e controle que devem ser adotadas durante a assistência aos casos suspeitos ou confirmados de infecção pelo novo coronavírus (COVID-19).

Cardoso, J. A. (2020). Pandemia e o regime especial de aulas não presenciais: analisando o modelo da Secretaria de Educação do Estado de GoiásSEDUC. Revista Aproximação, 2(5).

de Santana, L. S., Reis, T. E. B., Santos, L. H. D. A., \& Seixas, L. V. D. S. (2020). A arte de reinventar a educação e o papel da cibercultura em tempos de distanciamento social. Revista Interinstitucional Artes de Educar, 6, 301-324.

Fernández, S. (1993). La educación adaptativa como respuesta a la diversidad. Signos. Teoría y práctica de la educación, 8(9), 128-139.

Ferreira, A. B. D. H. (1988). Dicionário Aurélio básico da língua portuguesa.

Ferreira, V. E. S., Mesquita, J. M. C., Parente, P. D., da Costa Filho, L. G., Lima, M. G. F., \& de Aguiar, A. M. (2021). O agir da vigilância sanitária frente à covid-19 e o necessário exercício da intersetorialidade. Sanare-Revista de Políticas Públicas, 20.

Garcia, L. P., \& Duarte, E. (2020). Intervenções não farmacológicas para o enfrentamento à epidemia da COVID-19 no Brasil.

Gomes, V. T. S., Rodrigues, R. O., Gomes, R. N. S., Gomes, M. S., Viana, L. V. M., \& Silva, F. S. (2020). A pandemia da covid-19: repercussões do ensino remoto na formação médica. Revista Brasileira de Educação Médica, 44(4).

Hansen, J. T., Lambert, D., \& Oppido, T. (2007). Anatomia clínica de NETTER. Porto Alegre: Artmed. 
Research, Society and Development, v. 10, n. 7, e42110716923, 2021

(CC BY 4.0) | ISSN 2525-3409 | DOI: http://dx.doi.org/10.33448/rsd-v10i7.16923

Ludke, M. \& Andre, M. E. D. A. (2013). Pesquisas em educação: uma abordagem qualitativa. São Paulo: E.P.U.

Machado, R. (2018, October). Studygram: Interação e compartilhamento de processos de ensino-aprendizagem através do Instagram. In Brazilian Symposium on Computers in Education (Simpósio Brasileiro de Informática na Educação-SBIE) (Vol. 29, No. 1, p. 1964).

Martins, B. I., Albuquerque, L. C. E., \& Neves, M. (2018). Instagram Insights: Ferramenta de Análise de Resultados como Nova Estratégia de Marketing Digital. In XX Congresso de Ciências da Comunicação na Região Nordeste. Anais. Juazeiro.

Rondini, C. A., Pedro, K. M., \& dos Santos Duarte, C. (2020). Pandemia do Covid-19 e o ensino remoto emergencial: Mudanças na práxis docente. Interfaces Científicas-Educação, 10(1), 41-57.

Saldanha, L. C. D. (2020). O discurso do ensino remoto durante a pandemia de COVID-19. Revista Educação e Cultura Contemporânea, 17(50), 124-144. Santos, Edmea. (2019). Pesquisa-Formação na Cibercultura. Teresina: EDUFPI. 